\title{
Regioisomeric and enantiomeric analysis of primary triglycerides in human milk by silver ion and chiral HPLC atmospheric pressure chemical ionization-MS
}

\author{
Y. J. Chen, ${ }^{1}$ X. H. Zhou, ${ }^{2}$ B. Han, ${ }^{3}$ Zhuang Yu, ${ }^{4} \oplus$ H. X. Yi, ${ }^{1}$ @ S. L. Jiang, ${ }^{5}$ Y. Y. Li, ${ }^{5}$ J. C. Pan, ${ }^{5}$ \\ and L. W. Zhang ${ }^{1 *}$ \\ ${ }^{1}$ College of Food Science and Engineering, Ocean University of China, Qingdao, China 266003 \\ ${ }^{2}$ Qingdao Central Hospital, Qingdao 266042, China \\ ${ }^{3}$ Key Laboratory for Marine Bioactive Substances and Modern Analytical Technology, First Institute of Oceanography, \\ Ministry of Natural Resources, Qingdao 266061, China \\ ${ }^{4}$ Health Management Center, the Affiliated Hospital of Qingdao University, Qingdao, China 266000 \\ ${ }^{5}$ Heilongjiang Feihe Dairy Co. Ltd., Beijing 100015, China
}

\begin{abstract}
Triglycerides (TG) not only provide energy for infants but have important physiological functions. Understanding the composition and structure of TG in human milk is conducive to the development of infant formulas. In this study, TG species in human milk from 3 provincial capitals (Zhengzhou, Wuhan, and Harbin) in different regions of China were determined through C18 HPLC electrospray ionization tandem mass spectrometry (MS). The results showed that in human milk from these 3 regions, oleoyl-palmitoyl-linoleoylglycerol (OPL; $16.55,19.20$, and $18.67 \%$, respectively) was more abundant than oleoyl-palmitoyl-oleoylglycerol (OPO; $10.08,10.22$, and $12.03 \%$, respectively). Subsequently, regioisomeric and enantiomeric analysis of main TG in the human milk were performed on silver ion and chiral HPLC atmospheric pressure chemical ionization mass spectrometry (APCI)-MS, respectively. The results showed that rac-OPL (above 85\%), rac-OPO (above 85\%), rac-palmitoyl-oleoyl-oleoylglycerol (PPO; above $90 \%$ ), and rac-OLaO (above $70 \%$ ) were the main regioisomers of OPL, OPO, PPO, and lauroyl-oleoyloleoylglycerol ( $\mathrm{LaOO})$, respectively. The relative ratios of enantiomer pairs of rac-OPL (rac-OPL1 and racOPL2) were about 37 and $63 \%$, respectively.
\end{abstract}

Key words: human milk, triglycerides, regioisomers, enantiomers

\section{INTRODUCTION}

Human milk provides optimal natural nutrition for infants. Lipids, as the main energy source of human

Received July 30, 2019.

Accepted April 17, 2020.

*Corresponding author: zhanglanwei@ouc.edu.cn milk, $98 \%$ of which are represented by triglycerides (TG), provide about 50\% energy requirements for infants (Ten-Doménech et al., 2015). Triglycerides are esterified 3 fatty acids with a glycerol backbone and have a prochiral center at the secondary carbon of glycerol. Triglycerides may possess 3 different fatty acids (ABC type), 2 of the same fatty acids (AAB type), or 3 of the same fatty acids (AAA type). Different fatty acids esterified in the sn-2 and sn-1(3) positions result in regioisomers. Different fatty acids esterified in the sn- 1 and sn- 3 positions result in enantiomers ( ̌rezanka et al., 2016). It has been reported that 1,3-dioleoyl2-palmitoylglycerol (OPO) and 1-oleoyl-2-palmitoyl3-linoleoylglycerol (OPL) are the most predominant TG in human milk. The structure of TG, combined with a specific lipase in the gastrointestinal tract, causes a special process of fat digestion in infants. In infants' digestive systems, the expression of pancreatic triglyceride lipase (PTL), which has sn-1,3 regioselective, is not immaturity. Fat digestion in infants mainly depends on gastric lipase (HGL), pancreatic lipase-related protein 2, and bile salt-stimulated lipase (Bourlieu et al., 2014; Bourlieu and Michalski, 2015). Gastric lipase has strong sn-3 stereoselectivity, mainly releasing medium- and long-chain fatty acids in the stomach (Roman et al., 2007). The long-chain fatty acids released by HGL play an important role in triggering the activity of pancreatic lipase (Bernbäck et al., 1989). Meanwhile, fatty acid distribution in human milk TG are not random. Over $70 \%$ of the palmitic acid is esterified at the second (sn-2) carbon of the TG glycerol backbone, which reduces extraction of fecal soap fatty acids and calcium malabsorption, and promotes early bone mineralization (Wan et al., 2016; Miles and Calder, 2017). Thus, in human milk, not only the species of TG but also the regioisomers and enantiomers of TG play important nutritional and physiological 
roles. However, in human milk fat, only regioisomers of rac-palmitoyl-oleoyl-oleoylglycerol $(\mathbf{P P O}) /$ rac-POP and $\mathrm{rac}-\mathrm{OOP} / \mathrm{rac}-\mathrm{OPO}$ are separated and identified by silver ion chromatography (Zou et al., 2013a). The regioisomers of other important TG molecules, such as lauroyl-oleoyl-oleoylglycerol (LaOO) and OPL, were not yet separated. The enantiomers' separation of TG was not applied in human milk.

Various analytical methods have been used to identify the molecular structure of TG in human milk. Enzymatic (lipase) or chemical (Grignard) hydrolysis, combined with chromatography, have usually been used to analysis the regio- and stereospecific distribution of fatty acids in TG (Qi et al., 2018; Sun et al., 2018a). However, this has not separated the molecular species of TG, only determining mixed fatty acids on the primary and secondary hydroxyls. Reverse-phase liquid chromatography is a common method to separate TG species, which mainly depends on equivalent carbon numbers of TG (Řezanka et al., 2017). Partial separation of TG regioisomers in reverse-phase mode requires multiple column coupling and very long times (Momchilova et al., 2004; Momchilova et al., 2006). In human milk, C18 reverse-phase HPLC has usually been used to separate different species of TG (Pons et al., 2000; Beccaria et al., 2014). Reverse-phase liquid chromatography combined with MS detectors has also been used to analyze TG regioisomers in human milk (Kallio et al., 2017). It is well known that the intensities of diglyceride (DG) fragment ions $[\mathrm{M}+\mathrm{H}-\mathrm{RCOOH}]^{+}$depend on the positional distribution of fatty acids in TG; that is, the abundance of DG fragment ions resulting from loss of a fatty acid in the sn-2 position was less than that resulting from loss of a fatty acid from the sn-1 or 3 position (Lısa et al., 2009; Holčapek et al., 2010). But this method requires an extremely high number of reference compounds to obtain accurate correction factors, because each TG may have specific DG fragment ions ratios in MS. Therefore, up to now, integration of chromatographic peak area is still the most accurate method to determine the relative contents of regioisomers. Silver ion chromatography is a powerful technique for the separation of TG regioisomers, the retention time of which is mainly based on the number, geometry, and position of the double bones in the TG (rezanka et al., 2017). It has not been possible to identify TG enantiomers by MS, because enantiomers provide the same mass spectra due to loss of fatty acids from the sn-1 or sn-3 positions. Thus, distinguishing TG enantiomers requires standards. Only chiral phase chromatography has made it possible to separate enantiomers with their structures intact. The chiral stationary phases based on cellulose-tris-(3,5-dimethylphenylcarbamate) or cel- lulose-tris-(3-chlor-4-methyl phenyl carbamate) coated with silica gel have proved to be the most effective method. Chiral phase HPLC has many applications for separation of TG enantiomers, such as those of edible fats and oils (Kalpio et al., 2015), hazelnut oil, and human plasma (Lísa and Holčapek, 2013). But chiral phase HPLC has not yet been applied to the separation of enantiomers in human milk TG.

In this study, TG species in human milk from the cities of Zhengzhou (located in the Yellow River drainage area), Wuhan (located in the Yangtze River drainage area), and Harbin (located in Northeast China) were determined through C18 HPLC electrospray ionization (ESI)-MS/MS. Regioisomers and enantiomers of the main TG in human milk were also analyzed by silver ion and chiral HPLC atmospheric pressure chemical ionization (APCI)-MS, respectively.

\section{MATERIALS AND METHODS}

\section{Reagents and Standards}

The following racemic standards of TG were purchased from Larodan Fine Chemicals (Malmö, Sweden): rac-PPO, rac-POP, rac-OPO, rac-OOP, rac-LaOO, rac$\mathrm{OLaO}$, rac-OPL, rac-POL and rac-PLO. All solvents were HPLC or HPLC-MS grade and purchased from Merck (Darmstadt, Germany).

\section{Human Milk Samples}

Human milk was collected at 0900 to $1100 \mathrm{~h}$, before breastfeeding, from 4 to 6 mo after delivery. Volunteer mothers ( 25 to 35 yr old) from the hospitals in 3 provincial capitals, Zhengzhou (Zhenggong Hospital, $\mathrm{n}=30$ ), Wuhan (Zhoutoujie Health Service Center, Hanyang District, $\mathrm{n}=30$ ), and Harbin (Harbin Gongnong Community Health Service Center, $\mathrm{n}=30$ ), representing different regions of China, all received detailed information about the study and provided written informed consent. Mothers were physically healthy by self-evaluation, did not smoke, did not drink alcohol, and had given birth to physically healthy infants. Mothers were instructed to wash their hands carefully with soap and water before expressing milk from 1 breast by breast pump into sterile hard plastic containers. The collection human milk sample information was registered at ClinicalTrials.gov (ID: NCT03675204). All samples were kept frozen at $-20^{\circ} \mathrm{C}$ until delivery to the laboratory and then dispensed and stored at $-80^{\circ} \mathrm{C}$ for subsequent analysis. All samples were analyzed separately. 


\section{Extraction of Total Lipids from Human Milk}

Lipid samples from human milk were extracted using the Folch et al. (1957) procedure with modification. Briefly, $500 \mu \mathrm{L}$ of milk was mixed with $4.5 \mathrm{~mL}$ of chloroform and methanol $(2: 1, \mathrm{vol} / \mathrm{vol})$. The mixture was shaken and equilibrated with one-fourth volume of saline solution $(\mathrm{NaCl} 0.86 \%$, wt/wt). The solvent phase was filtered and dried under a stream of nitrogen. The obtained total lipids were stored at $-20^{\circ} \mathrm{C}$ for further analysis.

\section{TG Species Analysis}

Chromatographic Conditions. For chromatographic separation of TG, a Zorbax Eclipse Plus C18 column $(1.8 \mu \mathrm{m}, 2.1 \times 100 \mathrm{~mm}$, Agilent Technologies, Wilmington, DE) was used. The mobile phase gradients were as follows: 0 to 5 min $90 \% \mathrm{~A}+10 \% \mathrm{~B} ; 5$ to $25 \min 90-60 \% \mathrm{~A}+10-40 \% \mathrm{~B} ; 25$ to $60 \min 60-40 \%$ $\mathrm{A}+40-60 \% \mathrm{~B} ; 60$ to $66 \min 40 \% \mathrm{~A}+60 \% \mathrm{~B}$; where A was the mixture of acetonitrile, methanol, and water (19:19:2 by volume) with $10 \mathrm{~m} M$ ammonium acetate and $0.1 \%$ formic acid, and $\mathrm{B}$ was 2-propanol with 10 $\mathrm{m} M$ ammonium acetate and $0.1 \%$ formic acid. The flow rate was $0.2 \mathrm{~mL} / \mathrm{min}$, injection volume was $2 \mu \mathrm{L}$, column temperature was $45^{\circ} \mathrm{C}$, and sample concentration was $0.5 \mathrm{mg} / \mathrm{mL}$.

Qualitative Analysis. The qualitative analysis of TG used a Bruker maXis UHR-TOF-MS (Bruker Daltonics, Bremen, Germany) combined with UltiMate 3000 RSLCnano liquid chromatography (LC) system (Thermo Fisher Scientific, Waltham, MA). The chromatographic conditions were as previously described in the Chromatographic Conditions section. The parameters of qualitative time-of-flight MS were as follows: data acquisition was performed in positive ion ESI mode; source gas flow was $6 \mathrm{~L} / \mathrm{min}$; source temperature was $180^{\circ} \mathrm{C}$; and mass range $m / z$ was 50 to 1,200 .

Quantitative Analysis. Quantification of TG was performed on a Triple Quad LC-MS (Agilent) and by MS/MS using the multiple reaction monitoring acquisition mode. The chromatographic conditions were as previously described. The ESI source parameters, running in positive ionization mode, were $8 \mathrm{~L} / \mathrm{min}$ of drying gas $\left(\mathrm{N}_{2}\right), 350^{\circ} \mathrm{C}, 35$ psi of nebulizer pressure, and $3,500 \mathrm{~V}$ of capillary voltage.

Collection of PPO, POO, LaOO, and POL Fractions. The PPO, POO, LaOO, and POL fractions were collected from eluent of human milk TG using the Zorbax Eclipse Plus C18 column. The chromatographic conditions were as described. The sample concentration was $5 \mathrm{mg} / \mathrm{mL}$, and injection volume was $10 \mu \mathrm{L}$. The fractions corresponding to PPO, POO, LaOO, and
POL were collected by an automatic fraction collector. The sample volume of each fraction was about $0.4 \mathrm{~mL}$. Collected fractions were concentrated with nitrogen and redissolved with hexane to $50 \mu \mathrm{L}$ for further separation of regioisomers and enantiomers.

\section{Separation and Identification of Regioisomers and Enantiomers}

Separation of TG Regioisomers by Silver Ion HPLC. Separation of TG regioisomers was first performed on an Agilent 1290 Series liquid chromatograph, equipped with an evaporative light-scattering detector (ELSD) to determine the optimal chromatographic conditions. The ELSD was set at $40^{\circ} \mathrm{C}$ at a gas pressure of 30 psi and a gain value of 150 . A Varian ChromSpher 5 Lipids column $(5 \mu \mathrm{m}, 250 \mathrm{~mm} \times 4.6 \mathrm{~mm}$; Agilent $)$ was used to separate TG regioisomers, with a flow rate of $0.5 \mathrm{~mL} / \mathrm{min}$, injection volume of $5 \mu \mathrm{L}$, column temperature of $30^{\circ} \mathrm{C}$, and mobile phase gradient as follows: 0 to $20 \min 70 \% \mathrm{~A}+30 \% \mathrm{~B} ; 20$ to $21 \min 70-57 \% \mathrm{~A}$ + 30-43\% B; 21 to 45 min $57 \% \mathrm{~A}+43 \% \mathrm{~B}$, where A was hexane and $\mathrm{B}$ was a mixture of hexane-2-propanol $(98: 2, \mathrm{vol} / \mathrm{vol})$. The chromatographic system was equilibrated between injections for at least $30 \mathrm{~min}$. The reproducibility of the silver ion column with final chromatographic conditions was determined over $2 \mathrm{~d}$, each day including 5 consecutive injections.

Separation of TG Enantiomers by Chiral HPLC. Separation of TG enantioisomers (rac-OPL, rac-PLO, and rac-POL) was also first performed on the ELSD detector, to determine the optimal chromatographic conditions. The LC system used for separation in the chiral mode was as previously described. The final HPLC method for analyses of TG used the following conditions: a chiral chromatographic column Lux Cellulose-1 with cellulose-tris-(3,5-dimethyl phenylcarbamate)-coated silica gel as the stationary phase $(3 \mu \mathrm{m}, 250 \mathrm{~mm} \times 4.6 \mathrm{~mm}$, Phenomenex, Torrance, $\mathrm{CA}$ ), with flow rate of $0.5 \mathrm{~mL} / \mathrm{min}$, injection volume of $5 \mu \mathrm{L}$, column temperature of $30^{\circ} \mathrm{C}$, and mobile phase an isocratic elution of 0 to $180 \min 90 \% \mathrm{~A}+10 \%$ $\mathrm{B}$, where A was hexane and B was hexane-2-propanol (99:1, vol/vol) mixture. The reproducibility of the chiral column with final chromatographic conditions was determined over $2 \mathrm{~d}$, each day including 5 consecutive injections.

Identification of Regioisomers and Enantiomers by APCI-MS. The analysis regioisomers and enantiomers from human milk were performed on an HPLC APCI-MS. The LC system and chromatographic conditions were as previously described. The MS conditions were as follows: APCI source block and probe temperatures, 100 and $400^{\circ} \mathrm{C}$, respectively; MS 
multiplier voltage, $700 \mathrm{~V}$; measurement range, $\mathrm{m} / \mathrm{z}$ 200-1,500. The relative ratios of the regioisomers and enantiomers were obtained through the extracted ion chromatogram function.

\section{Statistical Analysis}

All analyses of human milk samples were carried out in triplicate. Results were expressed as means \pm standard deviations (SD). Data were subjected to oneway ANOVA and Tukey's test using SPSS version 20.0 (IBM Corp., Armonk, NY).

\section{RESULTS AND DISCUSSION}

\section{TG Profiling Analysis in Human Milk}

Reverse-phase HPLC (especially using a C18 column) is a common method to analyze TG, separating TG based on different equivalent carbon numbers $\mathrm{Hu}$ et al., 2013). In our study, the reverse-phase HPLC, combined with ESI-MS/MS full scan mode and ESI multiple reaction monitoring mode, were used to identify and quantify TG in human milk, respectively. The $\left[\mathrm{M}+\mathrm{NH}_{4}\right]^{+},[\mathrm{M}+\mathrm{H}]^{+}$, and $[\mathrm{DG}]^{+}$ions were first obtained using ESI full scan mode (Figure 1), and TG species were also identified. Then ion pairs of each TG were carefully chosen to quantify TG with multiple reaction monitoring mode.

Triglyceride species from 3 regions of China were analyzed and compared with each other to determine whether the relative abundances of TG have regional disparities, especially the contents of OPL and OPO. The results in Table 1 showed that in human milk from the 3 regions (Zhengzhou, Wuhan, and Harbin), the most abundant TG was OPL $(16.55,19.20$, and $18.67 \%$, respectively) and the second most abundant was OPO $(10.08,10.22$, and $12.03 \%$, respectively). The same results have been reported by other literature (in human milk samples from Wuxi, Beijing, Hubei, and Sichuan, respectively; Sun et al., 2018b). On the contrary, the most abundant TG in human milk samples from European countries is OPO, followed by OPL (Pons et al., 2000; Zou et al., 2013a; Ten-Doménech et al., 2015; Kallio et al., 2017). The composition of human milk components is related to multiple factors, including maternal diet, genetics, lactation stage, breastfeeding practices, maternal and infant health status, and environmental exposures (Miliku et al., 2019). Maternal diet has been considered the most important factor (Wang et al., 2020). The high levels of OPO in European countries are mainly related to the intake of olive oil (containing $63.3 \%$ oleic acid) by mothers, as in the Mediterranean diet in Spain, Italy, and Croatia. Other vegetable oils (such as peanut oil and rapeseed oil), nuts, meat, and cheese are also important sources of oleic acid (Orsavova et al., 2015; Barreiro et al., 2018). Therefore, contents of OPO and OPL are very different in different countries. In most Chinese cities, levels of OPL are higher than OPO. The TG with contents exceeding $4 \%$ in human milk from the 3 regions studied here (Zhengzhou, Wuhan, and Harbin) were PPO, PLL, OLL, and OOL, which are also the main TG in other literature results (Tu et al., 2017; Zhao et al., 2018). The contents of PPO in human milk from Harbin were significantly higher than those from Zhengzhou and Wuhan $(P<0.05)$. The contents of PLL, OLL, and OOL in human milk rom Wuhan were significantly higher than those from Zhengzhou and Harbin $(P<0.05)$. As for other major TG $(>1 \%)$, the contents of MLaLa, LaMM, LaLaO, MLLa, PLCa, POCa, MLaO, PMM, PPLa, PLLa, LOLa, MOPo, and LaOO in Zhenzhou human milk were significantly higher than those from Wuhan and Harbin $(P<0.05)$. Among these TG, the contents of LaMM, LaLaO, PLLa, LOLa, MOPo, and LaOO in Wuhan and Harbin human milk, and MLaLa and PPLa in Harbin human milk, exceeded 1\%; other TG relative values in Wuhan and Harbin human milk were less than $1 \%$. The contents of POM, PPP, and PPL in Harbin human milk were significantly higher than those in Zhengzhou and Wuhan samples $(P<$ $0.05)$. There were no significant differences in human milk from the 3 regions for the values of MMO, POLa, MOL, PLPo, and OOO. The results of our study and in the literature reveal that the TG containing linoleic acid, such as OPL, PLL, OLL, OOL, MOL, and LLL, in Chinese human milk were much higher than those in human milk from European countries (Zou et al., 2013b; Ten-Doménech et al., 2015; Sun et al., 2018b). This was consistent with the high levels of linoleic acid in Chinese human milk (Zou et al., 2016; Qi et al., 2018). High intake of soybean oil and sunflower oil, containing about 50 and $60 \%$ of linoleic acid, respectively, is mainly responsible for this phenomenon (Orsavova et al., 2015; Wang et al., 2020).

\section{Regioisomers of OPL, OPO, PPO, and LaOO}

Optimization of Silver Ion HPLC Conditions. In human milk, the regioisomers of OPO and PPO are usually separated using silver ion chromatography (Zou et al., 2013b), but the regioisomers of OPL, which is most abundant in Chinese human milk, have not been separated and analyzed by silver ion chromatography. Although the relative ratios of regioisomers of TG can be calculated based on the relative abundance of ion fragments produced by MS/MS product ion scan (Kallio et al., 2017), this method is limited by the high num- 

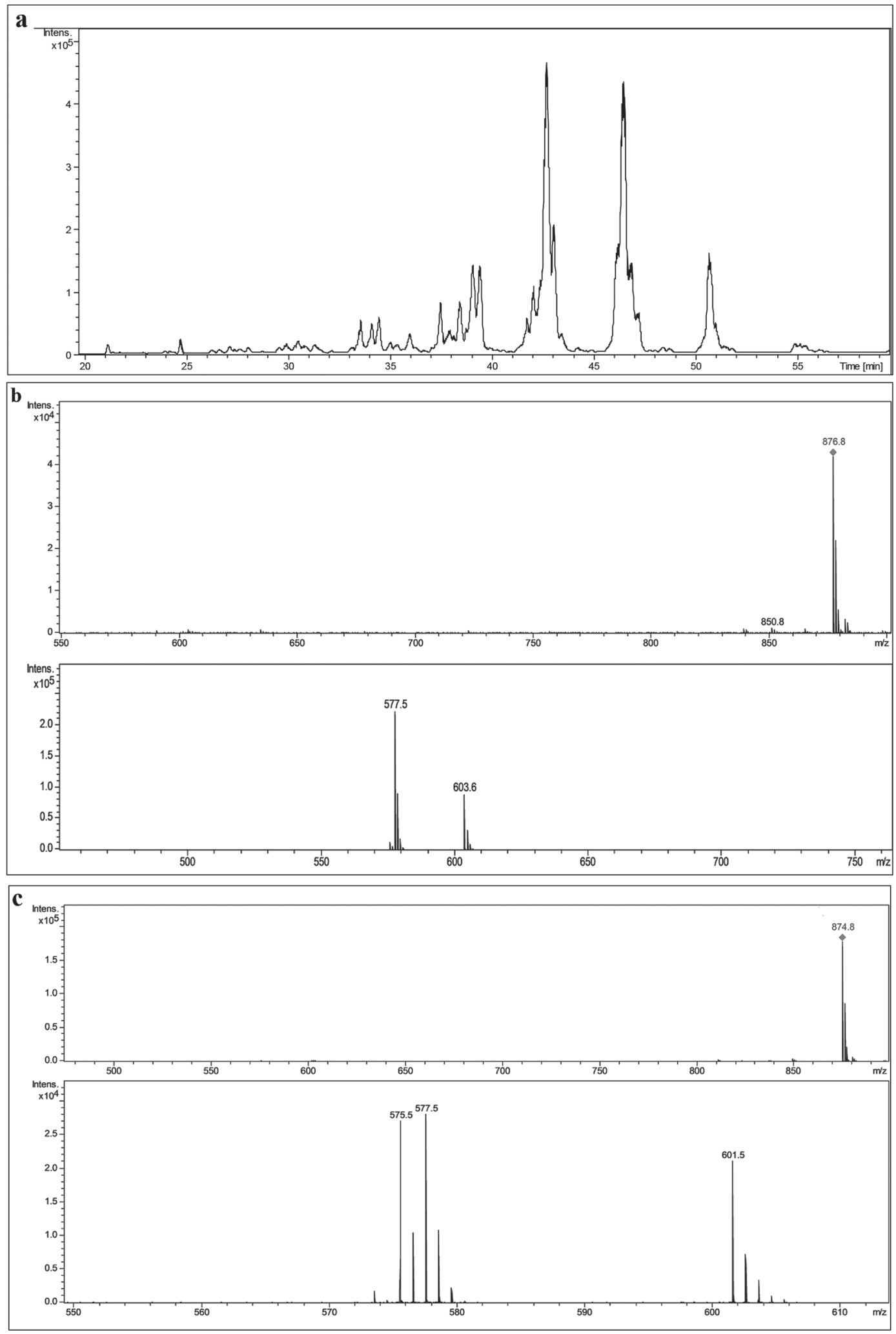

Figure 1. Analysis of human milk triglyceride (TG) species via C18 HPLC electrospray ionization-MS/MS. (a) Total ion chromatogram of human milk TG. (b) MS spectrum and MS/MS spectrum of oleoyl-palmitoyl-oleoylglycerol (OPO). (c) MS spectrum and MS/MS spectrum of oleoyl-palmitoyl-linoleoylglycerol (OPL). Intens. = intensity. 
Table 1. Triglyceride (TG) compositions in human milk from different cities in China (values given as mean $\pm \mathrm{SD})$

\begin{tabular}{|c|c|c|c|c|c|c|}
\hline \multirow[b]{2}{*}{$\mathrm{TG}^{1}$} & \multirow[b]{2}{*}{$\mathrm{ECN}^{2}$} & \multirow[b]{2}{*}{$\mathrm{CN}^{3}$} & \multirow[b]{2}{*}{$\mathrm{DB}^{4}$} & \multicolumn{3}{|c|}{ Sampling city } \\
\hline & & & & $\begin{array}{l}\text { Zhengzhou } \\
(\mathrm{n}=30)\end{array}$ & $\begin{array}{l}\text { Wuhan } \\
(\mathrm{n}=30)\end{array}$ & $\begin{array}{l}\text { Harbin } \\
(\mathrm{n}=30)\end{array}$ \\
\hline$\overline{\mathrm{PLaBu}}$ & 32 & 32 & 0 & $0.01 \pm 0.01^{\mathrm{a}}$ & $0.01 \pm 0.01^{\mathrm{a}}$ & $\mathrm{ND}^{5}$ \\
\hline $\mathrm{MMBu}$ & 32 & 32 & 0 & $0.01 \pm 0.01^{\mathrm{a}}$ & $0.02 \pm 0.01^{\mathrm{a}}$ & ND \\
\hline $\mathrm{LaOBu}$ & 32 & 34 & 1 & $0.01 \pm 0.00$ & ND & ND \\
\hline $\mathrm{LaLaCa}$ & 34 & 34 & 0 & $0.12 \pm 0.05^{\mathrm{b}}$ & $0.05 \pm 0.00^{\mathrm{a}}$ & $0.05 \pm 0.01^{\mathrm{a}}$ \\
\hline LaMC & 34 & 34 & 0 & $0.01 \pm 0.01^{\mathrm{a}}$ & $0.01 \pm 0.00^{\mathrm{a}}$ & $0.01 \pm 0.00^{\mathrm{a}}$ \\
\hline $\mathrm{PMBu}$ & 34 & 34 & 0 & $0.01 \pm 0.01^{\mathrm{a}}$ & $0.01 \pm 0.01^{\mathrm{a}}$ & ND \\
\hline $\mathrm{LCaC}$ & 32 & 36 & 2 & $0.04 \pm 0.02^{\mathrm{a}}$ & $0.02 \pm 0.01^{\mathrm{a}}$ & $0.02 \pm 0.01^{\mathrm{a}}$ \\
\hline $\mathrm{BuOM}$ & 34 & 36 & 1 & $0.01 \pm 0.01^{\mathrm{a}}$ & $0.01 \pm 0.01^{\mathrm{a}}$ & ND \\
\hline $\mathrm{SMBu}$ & 38 & 38 & 0 & $0.01 \pm 0.01^{\mathrm{a}}$ & $0.02 \pm 0.01^{\mathrm{a}}$ & $0.01 \pm 0.01^{\mathrm{a}}$ \\
\hline PLaC & 36 & 36 & 0 & $0.02 \pm 0.01^{\mathrm{a}}$ & $0.01 \pm 0.00^{\mathrm{a}}$ & $0.01 \pm 0.00^{\mathrm{a}}$ \\
\hline $\mathrm{PBuL}$ & 34 & 38 & 2 & $0.11 \pm 0.01^{\mathrm{a}}$ & $0.08 \pm 0.02^{\mathrm{a}}$ & $0.08 \pm 0.04^{\mathrm{a}}$ \\
\hline $\mathrm{LaCaL}$ & 36 & 40 & 2 & $0.02 \pm 0.01^{\mathrm{a}}$ & $0.01 \pm 0.00^{\mathrm{b}}$ & $0.01 \pm 0.00^{\mathrm{b}}$ \\
\hline $\mathrm{LaOC}$ & 36 & 38 & 1 & $0.07 \pm 0.02^{\mathrm{b}}$ & $0.03 \pm 0.00^{\mathrm{a}}$ & $0.02 \pm 0.02^{\mathrm{a}}$ \\
\hline $\mathrm{OCaCa}$ & 36 & 38 & 1 & $0.10 \pm 0.02^{\mathrm{b}}$ & $0.05 \pm 0.01^{\mathrm{a}}$ & $0.05 \pm 0.01^{\mathrm{a}}$ \\
\hline POBu & 36 & 38 & 1 & $0.11 \pm 0.00^{\mathrm{b}}$ & $0.05 \pm 0.02^{\mathrm{a}}$ & $0.05 \pm 0.02^{\mathrm{a}}$ \\
\hline MLaLa & 38 & 38 & 0 & $2.21 \pm 0.79^{\mathrm{b}}$ & $0.98 \pm 0.03^{\mathrm{a}}$ & $1.41 \pm 0.22^{\mathrm{ab}}$ \\
\hline PMC & 38 & 38 & 0 & $0.03 \pm 0.01^{\mathrm{a}}$ & $0.01 \pm 0.00^{\mathrm{a}}$ & $0.01 \pm 0.00^{\mathrm{a}}$ \\
\hline PPCp & 38 & 38 & 0 & $0.03 \pm 0.01^{\mathrm{a}}$ & $0.02 \pm 0.01^{\mathrm{a}}$ & $0.02 \pm 0.01^{\mathrm{a}}$ \\
\hline PSBu & 38 & 38 & 0 & $0.02 \pm 0.01^{\mathrm{a}}$ & $0.01 \pm 0.01^{\mathrm{a}}$ & $0.02 \pm 0.00^{\mathrm{a}}$ \\
\hline $\mathrm{BuOL}$ & 34 & 40 & 3 & $0.09 \pm 0.01^{\mathrm{b}}$ & $0.04 \pm 0.01^{\mathrm{a}}$ & $0.05 \pm 0.02^{\mathrm{a}}$ \\
\hline $\mathrm{BuOO}$ & 36 & 40 & 2 & $0.11 \pm 0.01^{\mathrm{b}}$ & $0.05 \pm 0.02^{\mathrm{a}}$ & $0.05 \pm 0.02^{\mathrm{a}}$ \\
\hline POCp & 38 & 40 & 1 & $0.11 \pm 0.01^{\mathrm{b}}$ & $0.06 \pm 0.02^{\mathrm{a}}$ & $0.04 \pm 0.02^{\mathrm{a}}$ \\
\hline OLaCa & 38 & 40 & 1 & $0.58 \pm 0.13^{\mathrm{b}}$ & $0.31 \pm 0.01^{\mathrm{a}}$ & $0.28 \pm 0.05^{\mathrm{a}}$ \\
\hline OCM & 38 & 40 & 1 & $0.05 \pm 0.02^{\mathrm{b}}$ & $0.02 \pm 0.01^{\mathrm{a}}$ & $0.02 \pm 0.00^{\mathrm{a}}$ \\
\hline LaMM & 40 & 40 & 0 & $1.87 \pm 0.63^{\mathrm{b}}$ & $1.10 \pm 0.02^{\mathrm{a}}$ & $1.04 \pm 0.24^{\mathrm{b}}$ \\
\hline $\mathrm{PPC}$ & 40 & 40 & 0 & $0.04 \pm 0.02$ & $0.02 \pm 0.01$ & $0.02 \pm 0.00$ \\
\hline PLC & 38 & 42 & 2 & $0.09 \pm 0.03^{\mathrm{b}}$ & $0.05 \pm 0.01^{\mathrm{a}}$ & $0.05 \pm 0.01^{\mathrm{a}}$ \\
\hline OOCp & 38 & 42 & 2 & $0.02 \pm 0.02^{\mathrm{a}}$ & $0.02 \pm 0.01^{\mathrm{a}}$ & $0.02 \pm 0.01^{\mathrm{a}}$ \\
\hline $\mathrm{LaLaO}$ & 40 & 42 & 1 & $1.87 \pm 0.43^{\mathrm{b}}$ & $1.10 \pm 0.08^{\mathrm{a}}$ & $1.84 \pm 0.12^{\mathrm{a}}$ \\
\hline POC & 40 & 42 & 1 & $0.20 \pm 0.04^{\mathrm{b}}$ & $0.09 \pm 0.02^{\mathrm{a}}$ & $0.09 \pm 0.02^{\mathrm{a}}$ \\
\hline PMLa & 42 & 42 & 0 & $0.78 \pm 0.23^{\mathrm{b}}$ & $0.42 \pm 0.03^{\mathrm{a}}$ & $0.58 \pm 0.11^{\mathrm{ab}}$ \\
\hline $\mathrm{PPCa}$ & 42 & 42 & 0 & $0.30 \pm 0.05^{\mathrm{b}}$ & $0.19 \pm 0.01^{\mathrm{a}}$ & $0.28 \pm 0.03^{\mathrm{b}}$ \\
\hline LLC & 36 & 44 & 4 & $0.04 \pm 0.00^{\mathrm{a}}$ & $0.02 \pm 0.01^{\mathrm{a}}$ & $0.02 \pm 0.01^{\mathrm{a}}$ \\
\hline LOC & 38 & 44 & 3 & $0.21 \pm 0.00^{\mathrm{b}}$ & $0.13 \pm 0.02^{\mathrm{a}}$ & $0.13 \pm 0.03^{\mathrm{a}}$ \\
\hline MLLa & 40 & 44 & 2 & $1.16 \pm 0.25^{\mathrm{b}}$ & $0.82 \pm 0.11^{\mathrm{a}}$ & $0.74 \pm 0.06^{\mathrm{a}}$ \\
\hline PLCa & 40 & 44 & 2 & $1.27 \pm 0.09^{\mathrm{b}}$ & $0.96 \pm 0.02^{\mathrm{a}}$ & $0.94 \pm 0.08^{\mathrm{a}}$ \\
\hline $\mathrm{POCa}$ & 42 & 44 & 1 & $1.10 \pm 0.06^{\mathrm{c}}$ & $0.78 \pm 0.00^{\mathrm{a}}$ & $0.90 \pm 0.05^{\mathrm{b}}$ \\
\hline $\mathrm{MLaO}$ & 42 & 44 & 1 & $1.03 \pm 0.21^{\mathrm{b}}$ & $0.67 \pm 0.07^{\mathrm{a}}$ & $0.68 \pm 0.09^{\mathrm{a}}$ \\
\hline PMM & 44 & 44 & 0 & $1.09 \pm 0.24^{\mathrm{b}}$ & $0.68 \pm 0.06^{\mathrm{a}}$ & $0.83 \pm 0.15^{\mathrm{a}}$ \\
\hline PPLa & 44 & 44 & 0 & $1.34 \pm 0.22^{\mathrm{b}}$ & $0.91 \pm 0.06^{\mathrm{a}}$ & $1.23 \pm 0.16^{\mathrm{b}}$ \\
\hline PSCa & 44 & 44 & 0 & $0.24 \pm 0.03^{\mathrm{b}}$ & $0.18 \pm 0.02^{\mathrm{a}}$ & $0.28 \pm 0.03^{\mathrm{c}}$ \\
\hline LLCa & 38 & 46 & 4 & $0.71 \pm 0.05^{\mathrm{b}}$ & $0.65 \pm 0.04^{\mathrm{ab}}$ & $0.53 \pm 0.10^{\mathrm{a}}$ \\
\hline PLLa & 42 & 46 & 2 & $1.95 \pm 0.16^{\mathrm{b}}$ & $1.64 \pm 0.22^{\mathrm{ab}}$ & $1.55 \pm 0.09^{\mathrm{a}}$ \\
\hline $\mathrm{OOCa}$ & 42 & 46 & 2 & $0.51 \pm 0.03^{\mathrm{b}}$ & $0.40 \pm 0.02^{\mathrm{ab}}$ & $0.28 \pm 0.14^{\mathrm{a}}$ \\
\hline MMO & 44 & 46 & 1 & $1.41 \pm 0.34^{\mathrm{a}}$ & $1.16 \pm 0.18^{\mathrm{a}}$ & $1.23 \pm 0.20^{\mathrm{a}}$ \\
\hline POLa & 44 & 46 & 1 & $2.68 \pm 0.19^{\mathrm{a}}$ & $2.08 \pm 0.21^{\mathrm{a}}$ & $2.13 \pm 0.45^{\mathrm{a}}$ \\
\hline $\mathrm{SOCa}$ & 44 & 46 & 1 & $0.12 \pm 0.01^{\mathrm{b}}$ & $0.10 \pm 0.00^{\mathrm{a}}$ & $0.11 \pm 0.01^{\mathrm{b}}$ \\
\hline PPM & 46 & 46 & 0 & $0.72 \pm 0.13^{\mathrm{a}}$ & $0.54 \pm 0.03^{\mathrm{a}}$ & $0.67 \pm 0.13^{\mathrm{a}}$ \\
\hline SPLa & 46 & 46 & 0 & $0.43 \pm 0.06^{\mathrm{b}}$ & $0.34 \pm 0.03^{\mathrm{a}}$ & $0.48 \pm 0.07^{\mathrm{b}}$ \\
\hline LLLa & 40 & 48 & 4 & $0.01 \pm 0.00^{\mathrm{a}}$ & $0.01 \pm 0.00^{\mathrm{a}}$ & $0.02 \pm 0.00^{\mathrm{a}}$ \\
\hline LOLa & 42 & 48 & 3 & $2.57 \pm 0.12^{\mathrm{b}}$ & $2.53 \pm 0.38^{\mathrm{b}}$ & $1.86 \pm 0.17^{\mathrm{a}}$ \\
\hline MOPo & 44 & 48 & 2 & $3.20 \pm 0.14^{\mathrm{c}}$ & $2.77 \pm 0.22^{\mathrm{b}}$ & $2.42 \pm 0.15^{\mathrm{a}}$ \\
\hline PML & 44 & 48 & 2 & $0.87 \pm 0.05^{\mathrm{a}}$ & $0.81 \pm 0.13^{\mathrm{a}}$ & $0.85 \pm 0.08^{\mathrm{a}}$ \\
\hline $\mathrm{LaOO}$ & 44 & 48 & 2 & $1.41 \pm 0.10^{\mathrm{b}}$ & $1.25 \pm 0.09^{\mathrm{ab}}$ & $1.15 \pm 0.01^{\mathrm{a}}$ \\
\hline POM & 46 & 48 & 1 & $1.32 \pm 0.09^{\mathrm{ab}}$ & $1.12 \pm 0.06^{\mathrm{a}}$ & $1.42 \pm 0.14^{\mathrm{b}}$ \\
\hline $\mathrm{PPP}$ & 48 & 48 & 0 & $1.34 \pm 0.06^{\mathrm{a}}$ & $1.21 \pm 0.08^{\mathrm{a}}$ & $1.81 \pm 0.33^{\mathrm{b}}$ \\
\hline SPM & 48 & 48 & 0 & $0.19 \pm 0.02^{\mathrm{a}}$ & $0.17 \pm 0.00^{\mathrm{a}}$ & $0.23 \pm 0.04^{\mathrm{a}}$ \\
\hline LLM & 42 & 50 & 4 & $1.25 \pm 0.08^{\mathrm{ab}}$ & $1.46 \pm 0.27^{\mathrm{b}}$ & $1.04 \pm 0.06^{\mathrm{a}}$ \\
\hline MOL & 44 & 50 & 3 & $3.85 \pm 0.18^{\mathrm{a}}$ & $3.66 \pm 1.25^{\mathrm{a}}$ & $3.31 \pm 0.17^{\mathrm{a}}$ \\
\hline PLPo & 44 & 50 & 3 & $1.36 \pm 0.32^{\mathrm{a}}$ & $1.16 \pm 0.12^{\mathrm{a}}$ & $1.39 \pm 0.17^{\mathrm{a}}$ \\
\hline PPL & 46 & 50 & 2 & $1.93 \pm 0.10^{\mathrm{a}}$ & $2.04 \pm 0.05^{\mathrm{a}}$ & $2.45 \pm 0.28^{b}$ \\
\hline $\mathrm{PPoO}$ & 46 & 50 & 2 & $0.86 \pm 0.16^{\mathrm{a}}$ & $0.71 \pm 0.08^{\mathrm{a}}$ & $0.93 \pm 0.08^{\mathrm{a}}$ \\
\hline MOO & 46 & 50 & 2 & $0.97 \pm 0.07^{\mathrm{a}}$ & $0.97 \pm 0.07^{\mathrm{a}}$ & $0.91 \pm 0.09^{\mathrm{a}}$ \\
\hline
\end{tabular}


Table 1 (Continued). Triglyceride (TG) compositions in human milk from different cities in China (values given as mean $\pm \mathrm{SD}$ )

\begin{tabular}{|c|c|c|c|c|c|c|}
\hline \multirow[b]{2}{*}{$\mathrm{TG}^{1}$} & \multirow[b]{2}{*}{$\mathrm{ECN}^{2}$} & \multirow[b]{2}{*}{$\mathrm{CN}^{3}$} & \multirow[b]{2}{*}{$\mathrm{DB}^{4}$} & \multicolumn{3}{|c|}{ Sampling city } \\
\hline & & & & $\begin{array}{l}\text { Zhengzhou } \\
(\mathrm{n}=30)\end{array}$ & $\begin{array}{c}\text { Wuhan } \\
(\mathrm{n}=30)\end{array}$ & $\begin{array}{c}\text { Harbin } \\
(\mathrm{n}=30)\end{array}$ \\
\hline$\overline{\mathrm{PPO}}$ & 48 & 50 & 1 & $4.57 \pm 0.22^{\mathrm{a}}$ & $4.48 \pm 0.19^{\mathrm{a}}$ & $5.98 \pm 0.78^{b}$ \\
\hline PPS & 50 & 50 & 0 & $0.30 \pm 0.01^{\mathrm{a}}$ & $0.30 \pm 0.04^{\mathrm{a}}$ & $0.48 \pm 0.12^{\mathrm{b}}$ \\
\hline MSS & 50 & 50 & 0 & $0.02 \pm 0.00^{\mathrm{a}}$ & $0.02 \pm 0.01^{\mathrm{a}}$ & $0.02 \pm 0.01^{\mathrm{a}}$ \\
\hline PoLL & 42 & 52 & 5 & $0.79 \pm 0.16^{\mathrm{a}}$ & $0.90 \pm 0.05^{\mathrm{a}}$ & $0.89 \pm 0.19^{\mathrm{a}}$ \\
\hline PLL & 44 & 52 & 4 & $6.56 \pm 0.81^{\mathrm{a}}$ & $8.22 \pm 0.10^{\mathrm{b}}$ & $7.38 \pm 0.65^{\mathrm{a}}$ \\
\hline OPL & 46 & 52 & 3 & $16.55 \pm 1.42^{\mathrm{a}}$ & $19.20 \pm 1.24^{\mathrm{b}}$ & $18.67 \pm 1.02^{\mathrm{a}}$ \\
\hline OPO & 48 & 52 & 2 & $10.08 \pm 0.67^{\mathrm{a}}$ & $10.22 \pm 1.04^{\mathrm{ab}}$ & $12.03 \pm 0.60^{b}$ \\
\hline POS & 50 & 52 & 1 & $0.97 \pm 0.05^{\mathrm{a}}$ & $1.03 \pm 0.14^{\mathrm{ab}}$ & $1.43 \pm 0.34^{b}$ \\
\hline PSS & 52 & 52 & 0 & $0.02 \pm 0.00^{\mathrm{a}}$ & $0.02 \pm 0.00^{\mathrm{a}}$ & $0.02 \pm 0.00^{\mathrm{a}}$ \\
\hline LLL & 42 & 54 & 6 & $1.91 \pm 0.20^{\mathrm{a}}$ & $2.96 \pm 0.19^{\mathrm{b}}$ & $2.17 \pm 0.48^{\mathrm{a}}$ \\
\hline OLL & 44 & 54 & 5 & $4.28 \pm 0.59^{\mathrm{a}}$ & $5.97 \pm 0.27^{\mathrm{b}}$ & $4.55 \pm 0.58^{\mathrm{a}}$ \\
\hline $\mathrm{OOL}$ & 46 & 54 & 4 & $4.83 \pm 0.46^{\mathrm{a}}$ & $5.66 \pm 0.22^{\mathrm{b}}$ & $4.92 \pm 0.48^{\mathrm{a}}$ \\
\hline $\mathrm{OOO}$ & 48 & 54 & 3 & $2.98 \pm 0.33^{\mathrm{a}}$ & $3.42 \pm 0.32^{\mathrm{a}}$ & $3.16 \pm 0.25^{\mathrm{a}}$ \\
\hline SOO & 50 & 54 & 2 & $0.40 \pm 0.09^{\mathrm{a}}$ & $0.49 \pm 0.08^{\mathrm{a}}$ & $0.53 \pm 0.11^{\mathrm{a}}$ \\
\hline SSO & 52 & 54 & 1 & $0.05 \pm 0.00^{\mathrm{a}}$ & $0.05 \pm 0.01^{\mathrm{a}}$ & $0.06 \pm 0.01^{\mathrm{a}}$ \\
\hline \multicolumn{7}{|c|}{${ }^{\mathrm{a}-\mathrm{c}}$ Different superscript letters indicate significant differences $(P<0.05)$ within a row. } \\
\hline $\begin{array}{l}{ }^{1} \mathrm{TG} \mathrm{n} \\
\text { caproi } \\
=\text { paln } \\
{ }^{2} \mathrm{ECN} \\
{ }^{3} \mathrm{CN}= \\
{ }^{4} \mathrm{DB}= \\
{ }^{5} \mathrm{ND}=\end{array}$ & $\begin{array}{l}\text { ot indic } \\
=\text { capryl } \\
\text { id; } \mathrm{S}= \\
\text { ent carb } \\
\text { on num } \\
\text { ond num } \\
\text { ted. }\end{array}$ & $\begin{array}{l}\text { ositiol } \\
\text { id; Ca } \\
\text { ic acid } \\
\text { umber } \\
\text { f TG. } \\
\text { of TG. }\end{array}$ & $\begin{array}{l}\text { ocation } \\
\text { apric a } \\
=\text { oleic } \\
\text { G. }\end{array}$ & $\begin{array}{l}\text { fatty acids in } \\
\mathrm{La}=\text { lauric ac } \\
\mathrm{id} ; \mathrm{L}=\text { linoleic }\end{array}$ & $\begin{array}{l}\text { iacylglycerols. B } \\
\text { I = myristic acid }\end{array}$ & $\begin{array}{l}\text { butyric acid; } \\
=\text { palmitic aci }\end{array}$ \\
\hline
\end{tabular}

ber of specific reference compounds required. At the same time, TG possesses the same molecular weight, but esterified with different fatty acids, and the same fragment ions may also be produced by MS/MS product ion scan. For example, LaLaO and POC produce the same $[\mathrm{DG}]^{+} 439.4$ and different $[\mathrm{DG}]^{+} 521.5,[\mathrm{DG}]^{+}$ 577.5, and 465.4, respectively. In this situation, depending only on ion fragment calculation to determine regioisomers was inaccurate. In human milk, lauric acid is the main medium-chain fatty acid and is usually supplemented in infant formulas, due to its rapid digestion and fast energy supplement $(\mathrm{Mu}$ and $\mathrm{H} \varnothing \mathrm{y}$, 2000; Sun et al., 2016). In our study LaOO was also the main TG $(>1 \%)$, and it has high contents reported in other literature results ( $>4 \%$; Zou et al., 2013a; TenDoménech et al., 2015; Sun et al., 2018b). Therefore, we selected the regioisomers of OPL, OPO, PPO, and $\mathrm{LaOO}$ to analyze via silver ion chromatography.

To best separation the regioisomers of PPO (rac$\mathrm{PPO} / \mathrm{rac}-\mathrm{POP}), \quad \mathrm{OPO}$ (rac-OPO/rac-OOP), LaOO (rac-LaOO/rac-OLaO), and OPL (rac-OPL/rac-POL/ rac-PLO), optimization chromatographic conditions of the silver ion column were performed on HPLC-ELSD equipment. It has been reported that, compared with a hexane-acetonitrile system, a hexane-2-propanol system can yield much better reproducibility of retention time for TG regioisomers, because 2-propanol possesses a higher mutual miscibility with hexane than acetoni- trile (Holčapek et al., 2010). In our study the hexane2 -propanol system was selected as the mobile phase. To precision-regulate the concentrations of 2-propanol, the mobile phase was prepared with 2 solvents, where A was hexane and $\mathrm{B}$ was a mixture of hexane and 2-propanol (99:2). The mobile phase gradients $20 \% \mathrm{~A}+80 \%$ $\mathrm{B}, 60 \% \mathrm{~A}+40 \% \mathrm{~B}, 65 \% \mathrm{~A}+35 \% \mathrm{~B}$, and $60 \% \mathrm{~A}+$ $30 \% \mathrm{~B}$ were used to determine optimal gradient composition, at a flow rate of $0.5 \mathrm{~mL} / \mathrm{min}$ and a column temperature of $30^{\circ} \mathrm{C}$. The results showed that decreasing the percentage of mobile phase $\mathrm{B}$ resulted in higher chromatographic resolution and longer retention time (Supplemental Figure S1; https://doi.org/10.3168/jds .2019-17353). The mobile phase gradient of $65 \% \mathrm{~A}+$ $35 \%$ B was selected to determine the effects of column temperature $\left(20^{\circ} \mathrm{C}, 30^{\circ} \mathrm{C}\right.$, or $\left.40^{\circ} \mathrm{C}\right)$ and flow rate $(0.3$ $\mathrm{mL} / \mathrm{min}, 0.5 \mathrm{~mL} / \mathrm{min}$, or $1 \mathrm{~mL} / \mathrm{min}$ ) on the resolution of regioisomers. The change of flow rate can also strongly influence the chromatographic resolution of regioisomers and retention times. With increasing flow rate, chromatographic resolution decreased, and shorter retention times appeared (Supplemental Figure S2; https://doi.org/10.3168/jds.2019-17353). The column temperature had a slight effect on the chromatographic resolution and retention time. The increase of column temperature from $20^{\circ} \mathrm{C}$ to $40^{\circ} \mathrm{C}$ resulted in increased retention time of PPO, OPO, and LaOO. Although the retention times of $\mathrm{OPL}$ at $20^{\circ} \mathrm{C}$ and $40^{\circ} \mathrm{C}$ were longer 
than at $30^{\circ} \mathrm{C}$, chromatographic resolution showed no obvious change (Supplemental Figure S3; https://doi .org/10.3168/jds.2019-17353). The best separation of individual isomers is achieved at $30^{\circ} \mathrm{C}$. It has been reported that increasing the silver ion column temperature results in significantly increased retention time of TG (Adlof and List, 2004). Finally, chromatographic conditions were as follows: $0-20 \min 70 \% \mathrm{~A}+30 \% \mathrm{~B}$, 20-21 min, $70-57 \% \mathrm{~A}+30-43 \% \mathrm{~B}, 21-45 \min 57 \%$ $\mathrm{A}+43 \% \mathrm{~B}$, where $\mathrm{A}$ was hexane, $\mathrm{B}$ was the mixture of hexane-2-propanol $(98: 2, \mathrm{vol} / \mathrm{vol})$, with a flow rate of $0.5 \mathrm{~mL} / \mathrm{min}$, injection volume of $5 \mu \mathrm{L}$, and column temperature of $30^{\circ} \mathrm{C}$. Good reproducibility of retention time was obtained under these chromatographic conditions, as the relative SD of retention times were 0.32 , $0.34,0.45,0.47,0.51,0.74,0.77$, and $0.83 \%$ for 5 consecutive injections in the first day measurements and $0.65,0.67,1.13,1.16,1.27,1.28,1.51$, and $1.76 \%$ for 5 consecutive injection in the second day measurements, respectively (Supplemental Figure S4; https://doi.org/ 10.3168/jds.2019-17353).

It was observed that the regioisomers of rac-POP/ $\mathrm{rac}-\mathrm{OOP}, \mathrm{rac}-\mathrm{OPO} / \mathrm{rac}-\mathrm{OOP}, \mathrm{rac}-\mathrm{LaOO} / \mathrm{rac}-\mathrm{OLaO}$, and rac-OPL/rac-POL/rac-PLO can be separated with each other, but a strong overlap appeared between rac-OPO and rac-LaOO (Figure 2a). Coinstantaneous separation of rac-PPO, rac-POP, rac-POO, rac-OPO, rac-LaOO and rac-OLaO, rac-POL, rac-PLO, and racOPL by silver ion chromatography only may take a very long time. It is well known that APCI-MS can identify TG based on $[\mathrm{M}+\mathrm{H}]^{+}$and $[\mathrm{DG}]^{+}$ions in a strong nonpolar environment (Lísa et al., 2009). Thus, we replaced ELSD detector with APCI-MS to analyze regioisomers of TG in human milk samples. The results in Figure $2 \mathrm{~b}$ and $\mathrm{c}$ show that APCI-MS can distinguish well between rac-OPO and rac-LaOO by extracted ion chromatogram. Therefore, HPLC APCI-MS was finally used to identify the regioisomers of $\mathrm{PPO}$ ( rac-PPO/racPOP), OPO (rac-OPO/rac-OOP), LaOO (rac-LaOO/ $\mathrm{rac}-\mathrm{OLaO}$ ), and OPL (rac-OPL/rac-POL/rac-PLO), with chromatographic conditions as described earlier.

Regioisomers of PPO,OPO,LaOO, and OPL in Human Milk. The relative ratios of TG regioisomers are important to the digestion and absorption of human milk fat in infants, for the specific lipase selectivity in infant digestive system. In human milk, palmitic acid esterified at sn-2 position is associated with improved bone strength, increased fecal bifidobacteria, and reduced crying in infants (Miles and Calder, 2017). The regioisomers of $\mathrm{PPO}$ (rac-PPO/rac-POP), OPO (rac-OPO/rac-OOP), LaOO (rac-LaOO/rac-OLaO), and OPL (rac-OPL/rac-POL/rac-PLO) in human milk from Zhengzhou, Wuhan, and Harbin were analyzed by 2 -dimensional chromatography of reverse-phase and silver ion HPLC combined with APCI-MS. Twodimensional HPLC in online or offline mode is a practical method to analyze isomers in complex samples, especially in milk samples, which can effectively avoid the distraction of other TG. It is observed that the relative ratios of regioisomers of $\mathrm{PPO}$ (rac- $\mathrm{PPO} / \mathrm{rac}-$ POP), OPO (rac-OPO/rac-OOP), LaOO (rac-LaOO/ $\mathrm{rac}-\mathrm{OLaO}$ ), and OPL (rac-OPL/rac-POL/rac-PLO) can be well obtained by extracted ion chromatogram (Figure 3). The relative ratios of regioisomers of OPO, PPO, and OPL also illustrate the important role of sn-2 position palmitic acid. The results showed that in human milk, the main regioisomers of PPO, OPO, and OPL were rac-PPO, rac-OPO, and racc-OPL, respectively (Table 2 ). The relative ratios of regioisomers of PPO (rac-PPO/rac-POP) in human milk from the 3 studied regions had no statistical differences. In Zhengzhou, Wuhan, and Harbin, the relative ratios of rac-PPO were 93.92, 94.41, and 93.81\%, respectively, and rac-POP were $6.08,5.59$, and $6.19 \%$, respectively. The regioisomers of OPL (rac-OPL and rac-POL) also showed no obvious differences among human milk from the 3 regions. In the 3 regions, the relative ratios of racOPL were $90.59,86.63$, and $85.59 \%$, respectively, and those of rac-POL were $4.22,6.06$, and $6.66 \%$, respectively. The contents of rac-PLO $(5.19 \%)$ in Zhengzhou human milk were lower than those in milk from Wuhan and Harbin, 7.30 and $7.75 \%$, respectively. In the case of the regioisomers of OPO, human milk from Zhengzhou possessed higher rac-OPO $(88.46 \%)$ than Harbin $(84.65 \%)$ and Wuhan $(86.65 \%)$. The relative ratios of rac-OPO and rac-OPL occupied above $85 \%$ of OPO and OPL, respectively, the 2 most abundant TG in human milk. This phenomenon revealed that, besides rac-OPO, rac-OPL should also be prepared and added to infant formulas. The main regioisomer of $\mathrm{LaOO}$ is rac-OLaO, the relative ratios of which in Zhengzhou, Wuhan, and Harbin were 73.40, 71.95, and $74.97 \%$, respectively. Results in other literature have also reported most lauric acid at sn-2 position of TG in human milk (Kallio et al., 2017).

\section{Enantiomer Pairs of Rac-OPL}

Optimization of Chiral HPLC Conditions. The most important ABC type of TG in human milk, OPL has not only regioisomers but enantiomers. In infants' digestion systems, HGL may be the only lipase that has sn-3 stereoselectivity (Roman et al., 2007). The limited hydrolysis of milk TG by HGL could trigger the activity of bile salt-stimulated lipase and pancreatic lipaserelated protein 2 (Bernbäck et al., 1990). Thus, we also analyzed the enantiomers of OPL. A chiral HPLC column packed with cellulose-tris-3,5-dimethylphenyl- 
a

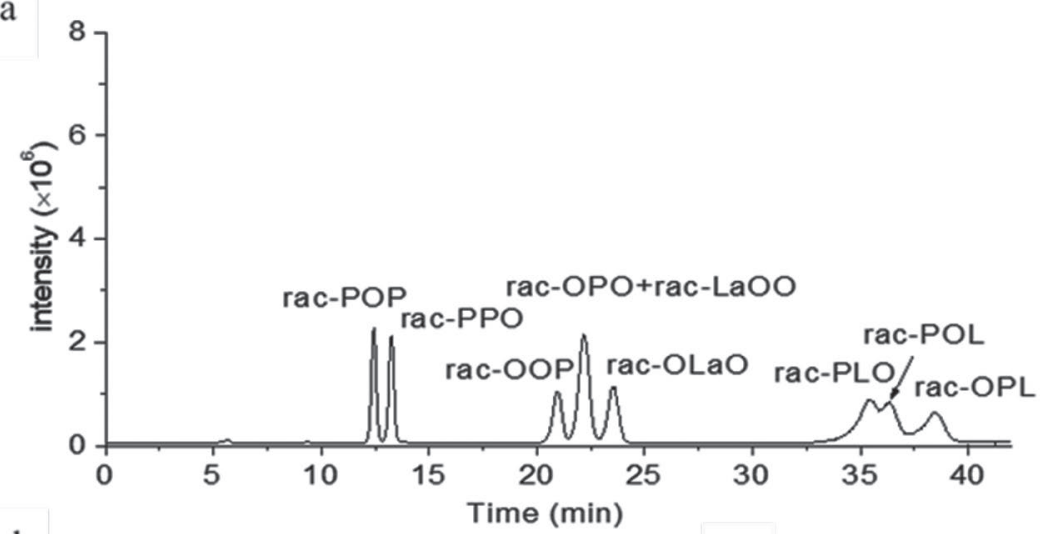

b

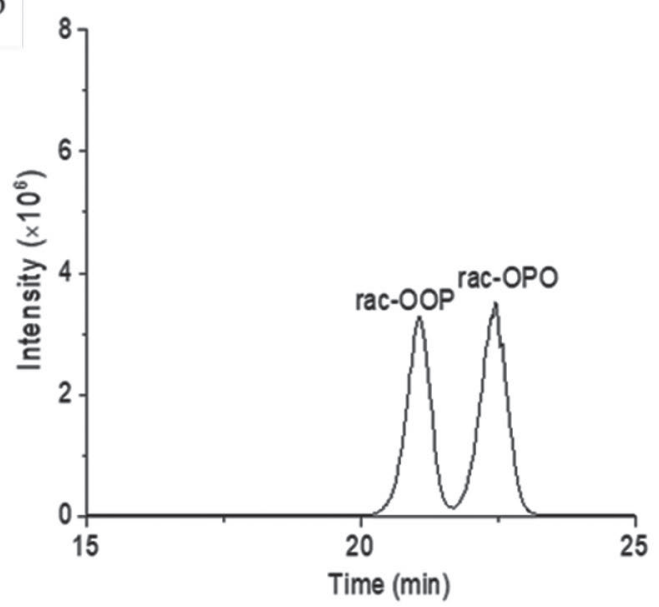

c

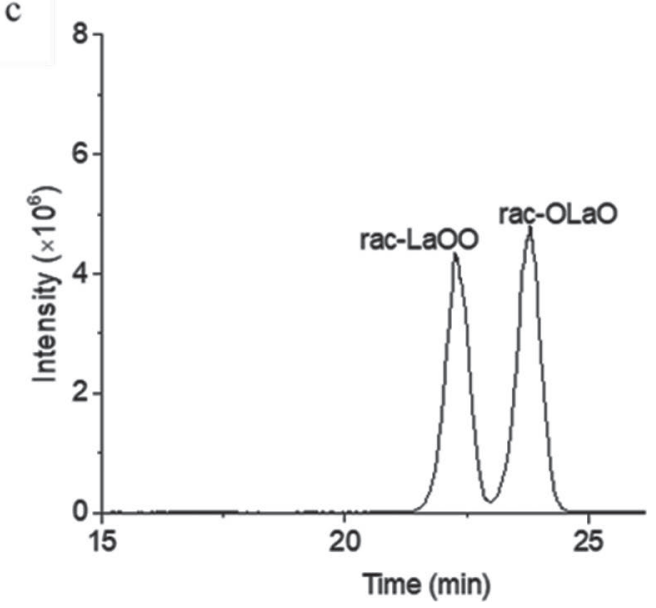

Figure 2. Silver ion HPLC atmospheric pressure chemical ionization-MS analysis of triglyceride (TG) standards. (a) Total ion chromatogram of TG in the regioisomers of PPO (rac-PPO/rac-POP), oleoyl-palmitoyl-oleoylglycerol (OPO; rac-OPO/rac-OOP), lauroyl-oleoyl-oleoylglycerol (LaOO; rac-LaOO/rac-OLaO), and POL [rac-oleoyl-palmitoyl-linoleoylglycerol (OPL)/rac-POL/rac-PLO]. (b) Extract ion chromatogram of rac-OOP and rac-OPO. (c) Extract ion chromatogram of rac-LaOO and rac-OLaO.

carbamate was used for separation of the enantiomers of rac-OPL, rac-POL, and rac-PLO. The selection of mobile phase composition was based on the literature results of Lísa and Holčapek (2013), who reported that hexane-2-propanol was a better mobile phase system for separation TG enantiomers compared with hexane-acetonitrile-2-propanol and hexane-acetonitrile mixtures, which can separate enantiomeric pairs with 1 to 3 DB. But the isomers of OPL were not separated in their experiments. Therefore, new chromatographic conditions should be optimized to determine the enantiomers of rac-OPL, rac-PLO and rac-POL in human milk. The mobile chiral phase was composed of hexane (A) and a mixture of hexane:2-propanol, 99:1 (B). The standard of rac-OPL was first eluted with mobile phase compositions of $40 \% \mathrm{~A}+60 \% \mathrm{~B}, 50 \% \mathrm{~A}+50 \% \mathrm{~B}, 75 \%$ $\mathrm{A}+25 \% \mathrm{~B}$, and $90 \% \mathrm{~A}+10 \% \mathrm{~B}$, respectively, at a column temperature of $30^{\circ} \mathrm{C}$ and a flow rate of $0.5 \mathrm{~mL} /$ min. The results showed that increasing the concentrations of 2-propanol resulted in shortened retention time and lower chromatographic resolution of enantiomeric pairs (Supplemental Figure S5; https://doi.org/10 .3168/jds.2019-17353). Then the standards of rac-PLO and rac-POL, and the mixture of rac-OPL/rac-PLO/ rac-POL, were eluted with a mobile phase composition of $90 \% \mathrm{~A}+10 \% \mathrm{~B}$, at a column temperature of $30^{\circ} \mathrm{C}$ and a flow rate of $0.5 \mathrm{~mL} / \mathrm{min}$. It has been observed that the enantiomeric pairs of rac-OPL and rac-PLO can be separated into 2 enantiomers, rac-OPL1/racOPL2 and rac-PLO1/rac-PLO 2, respectively (Figure $4 \mathrm{a}, \mathrm{b}$ ). But rac-POL cannot be separated at all (Figure 4c). The mixture of rac-OPL/rac-PLO/rac-POL appeared strongly overlapped and was very difficult to simultaneously separate into 6 enantiomers (Figure 4d). Therefore, the enantiomers of rac-OPL, rac-PLO, and rac-POL were considered to separate respectively. Flow rate and column temperature were also valid factors affecting resolution of enantiomeric pairs. In our study, rac-OPL was selected to determine the optimal column temperature and flow rate. The results showed that 

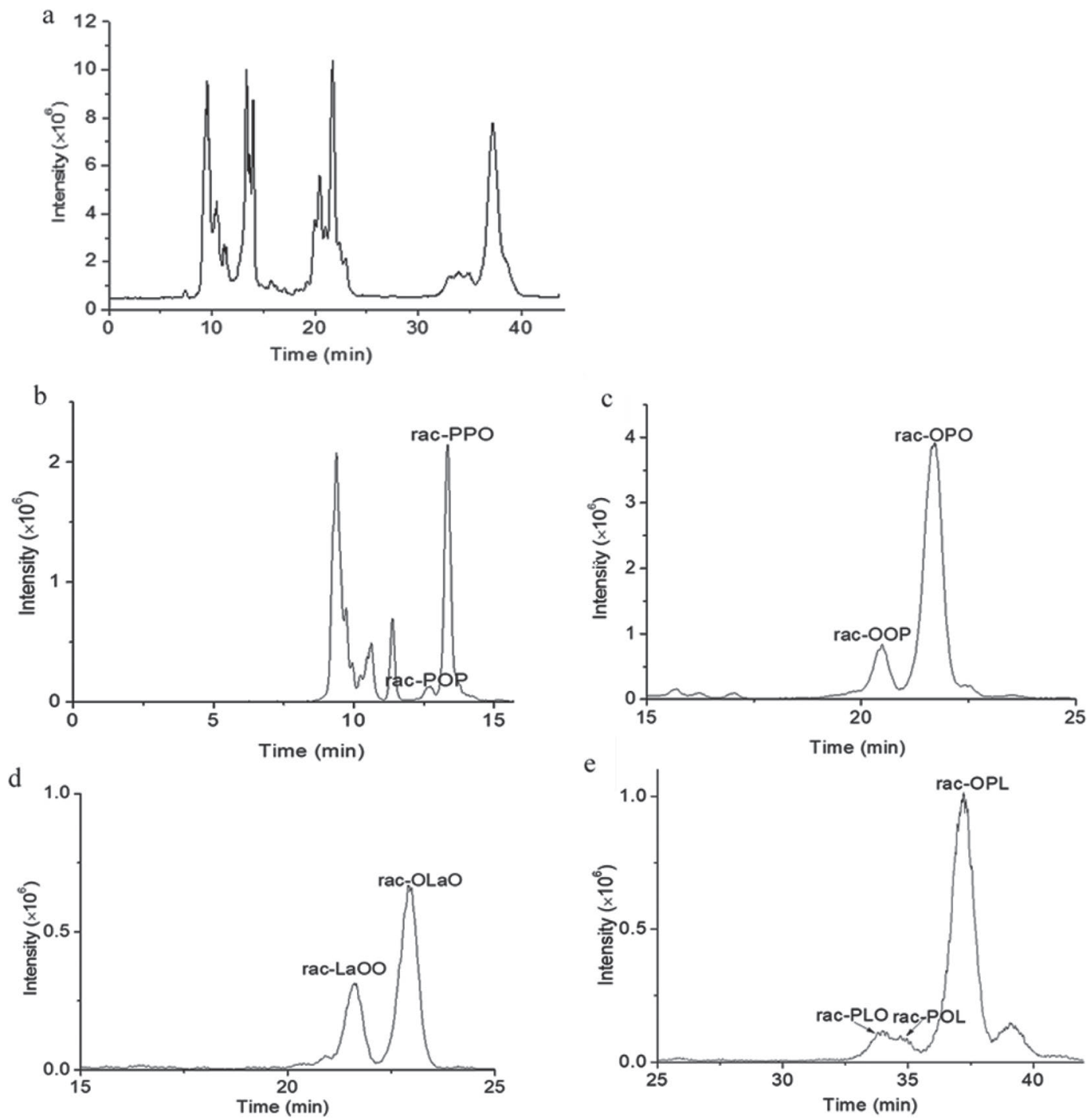

Figure 3. Silver ion HPLC atmospheric pressure chemical ionization-MS analysis of human milk regioisomers. (a) Total ion chromatogram of triglycerides in the regioisomers of PPO (rac-PPO/rac-POP), oleoyl-palmitoyl-oleoylglycerol (OPO; rac-OPO/rac-OOP), lauroyl-oleoyl-oleoylglycerol (LaOO; rac-LaOO/rac-OLaO), and OPL (rac-OPL/rac-POL/rac-PLO). (b) Extract ion chromatogram of rac-POP and rac-PPO. (c) Extract ion chromatogram of rac-OOP and rac-OPO. (d) Extract ion chromatogram of rac-lauroyl-oleoyl-oleoylglycerol (LaOO) and rac-OLaO. (e) Extract ion chromatogram of rac-PLO, rac-POL and rac-OPL.

increasing column temperature and flow rate caused shortened retention time and lower chromatographic resolution of enantiomeric pairs (Supplemental Figure S6-S7; https://doi.org/10.3168/jds.2019-17353). Thus, column temperature and flow rate were set to $30^{\circ} \mathrm{C}$ and $0.5 \mathrm{~mL} / \mathrm{min}$, respectively. Separation of TG enantiomers is mainly based on DB numbers, and the DB numbers of outer position (sn-1 and sn-3) esterified fatty acyls had no significant influence by fatty acyl in sn-2 position (Lísa and Holčapek, 2013; Řezanka et al., 2013; Řezanka and Sigler, 2014). Palmitic acid, linoleic acid, and oleic acid, containing similar chain length and low DB numbers, may be responsible for the overlap of rac-OPL, rac-PLO, and rac-POL. Thus, it is a challenge to separate OPL into 6 isomers (regioand enantio-isomers). The results for rac-POL, having combinations of saturated and di-unsaturated fatty acyls in the sn- 1 and sn-3 positions, not separated into 2 enantiomer pairs, were same as the results reported by Lísa and Holčapek (2013). Optimization conditions were determined for chromatographic resolution of rac-OPL and rac-PLO enantiomeric pairs, respectively. The final method was as described previously. The reproducibility of rac-OPL1 and rac-OPL2 retention times was determined. Relative SD of retention times under final chromatographic conditions were 0.44 and 
Table 2. Relative ratios of regioisomers of OPO, PPO, LaOO, and OPL in human milk from 3 cities in China (values given as mean $\pm \mathrm{SD}$ )

\begin{tabular}{llccr}
\hline & & \multicolumn{3}{c}{ Relative ratio $(\%)$} \\
\cline { 3 - 5 } $\mathrm{TG}^{1}$ & Regioisomers & $\begin{array}{c}\text { Zhengzhou } \\
(\mathrm{n}=30)\end{array}$ & $\begin{array}{c}\text { Wuhan } \\
(\mathrm{n}=30)\end{array}$ & $\begin{array}{c}\text { Harbin } \\
(\mathrm{n}=30)\end{array}$ \\
\hline POP & rac-POP & $6.08 \pm 0.88^{\mathrm{a}}$ & $5.59 \pm 0.98^{\mathrm{a}}$ & $6.19 \pm 2.29^{\mathrm{a}}$ \\
& rac-PPO & $93.92 \pm 0.88^{\mathrm{a}}$ & $94.41 \pm 0.98^{\mathrm{a}}$ & $93.81 \pm 2.29^{\mathrm{a}}$ \\
LaOO & rac-LaOO & $26.60 \pm 1.88^{\mathrm{a}}$ & $28.05 \pm 4.52^{\mathrm{a}}$ & $25.03 \pm 2.62^{\mathrm{a}}$ \\
& rac-OLaO & $73.40 \pm 1.88^{\mathrm{a}}$ & $71.95 \pm 4.52^{\mathrm{a}}$ & $74.97 \pm 2.62^{\mathrm{a}}$ \\
POO & rac-OOP & $11.54 \pm 0.51^{\mathrm{a}}$ & $13.64 \pm 2.57^{\mathrm{ab}}$ & $14.35 \pm 1.11^{\mathrm{b}}$ \\
& rac-OPO & $88.46 \pm 0.51^{\mathrm{b}}$ & $86.36 \pm 2.57^{\mathrm{ab}}$ & $85.65 \pm 1.11^{\mathrm{a}}$ \\
& rac-PLO & $5.19 \pm 1.02^{\mathrm{a}}$ & $7.30 \pm 0.19^{\mathrm{b}}$ & $7.75 \pm 1.09^{\mathrm{b}}$ \\
& rac-POL & $4.22 \pm 1.23^{\mathrm{a}}$ & $6.06 \pm 1.84^{\mathrm{a}}$ & $6.66 \pm 3.56^{\mathrm{a}}$ \\
& rac-OPL & $90.59 \pm 2.09^{\mathrm{a}}$ & $86.63 \pm 1.73^{\mathrm{a}}$ & $85.59 \pm 4.63^{\mathrm{a}}$ \\
\hline
\end{tabular}

${ }_{\mathrm{a}, \mathrm{b}}$ Different superscript letters indicate significant differences $(P<0.05)$ within a row.

${ }^{1} \mathrm{TG}=$ triglycerides. Names do not indicate positional location of fatty acids in the triacylglycerols. La $=$ lauric acid; $\mathrm{P}=$ palmitic acid; $\mathrm{L}=$ linoleic acid; $\mathrm{O}=$ oleic acid.

$0.46 \%$ for 1 -d measurements and 1.11 and $1.32 \%$ for 2-d measurements, demonstrating good reproducibility (Supplemental Figure S8; https://doi.org/10.3168/jds .2019-17353).

Enantiomer Pairs of Rac-OPL in Human Milk. The main regioisomer of OPL-TG in human milk was rac-OPL (above 85\%). Therefore, only enantiomer pairs of rac-OPL were really determined in the human milk samples, because the contents of rac-PLO were too low and difficult to collect, and rac-POL failed to separate into 2 enantiomer pairs. To avoid interference of other TG, enantiomer pairs of rac-OPL (rac-OPL1 and rac-OPL2) in human milk were analyzed using chiral HPLC APCI-MS, with chromatographic conditions a

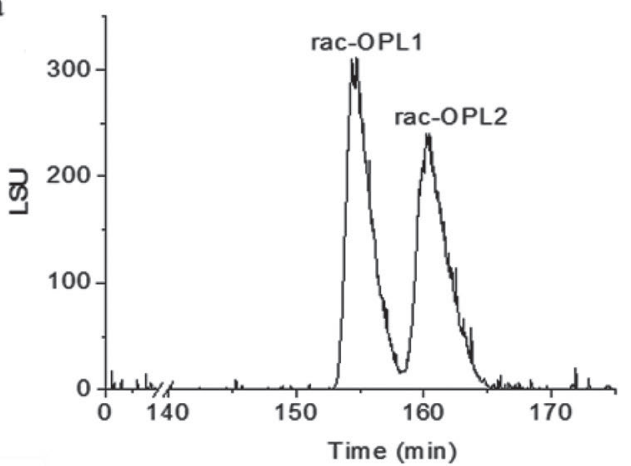

c

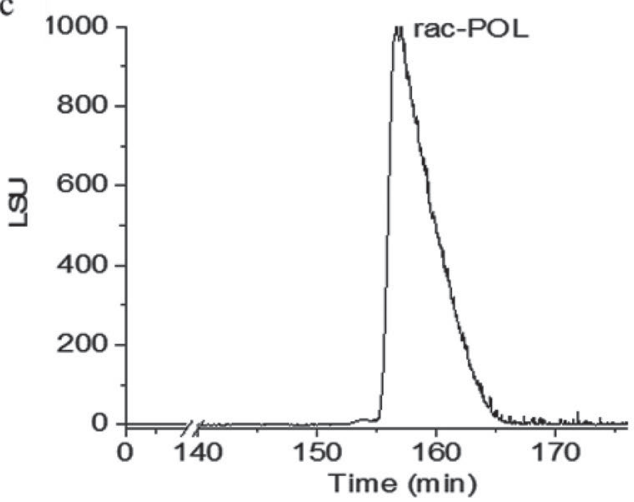

b

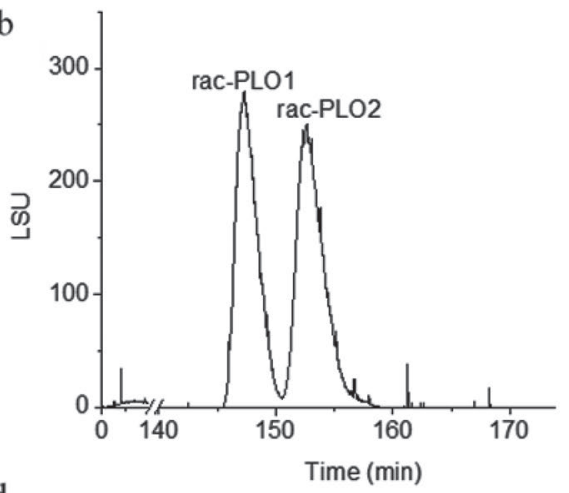

d

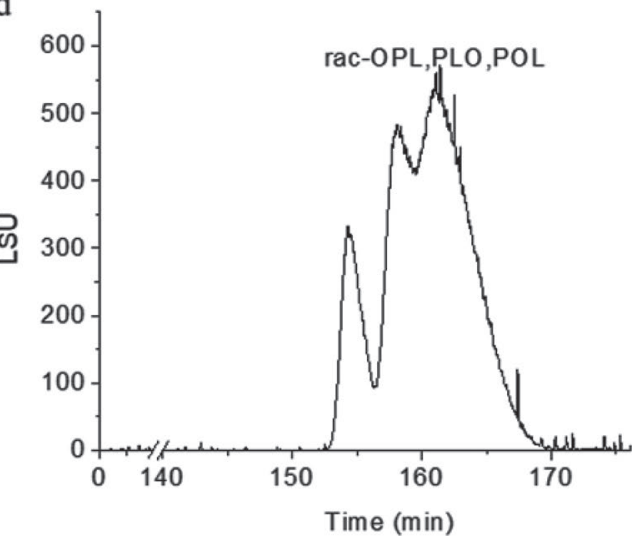

Figure 4. Chiral HPLC evaporative light-scattering detector analysis of enantiomers of 1-oleoyl-2-palmitoyl-3-linoleoylglycerol (OPL). (a) Enantiomer pairs of rac-OPL (rac-OPL1 and rac-OPL2). (b) Enantiomers pairs of rac-PLO (rac-PLO1 and rac-PLO2). (c) Rac-POL. (d) The mixture of rac-OPL, rac-PLO, and rac-POL. LSU = light scattering units. 


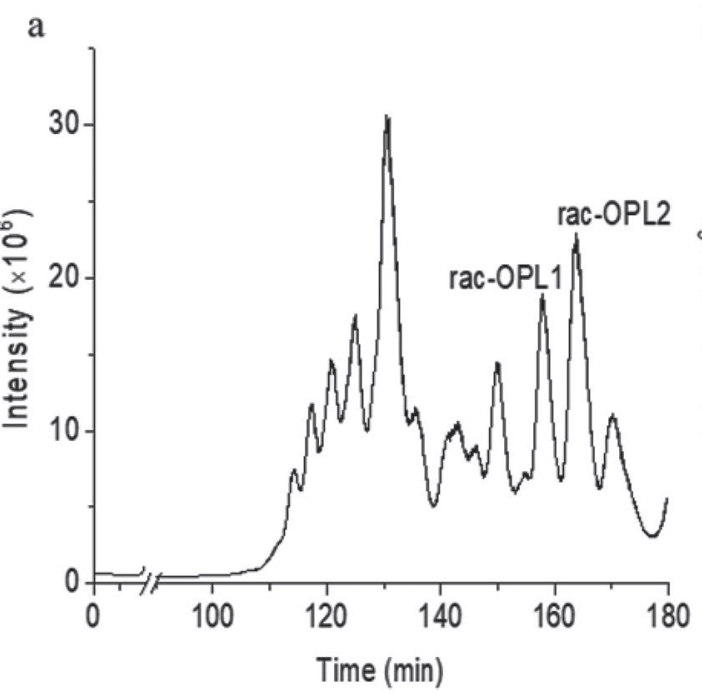

b

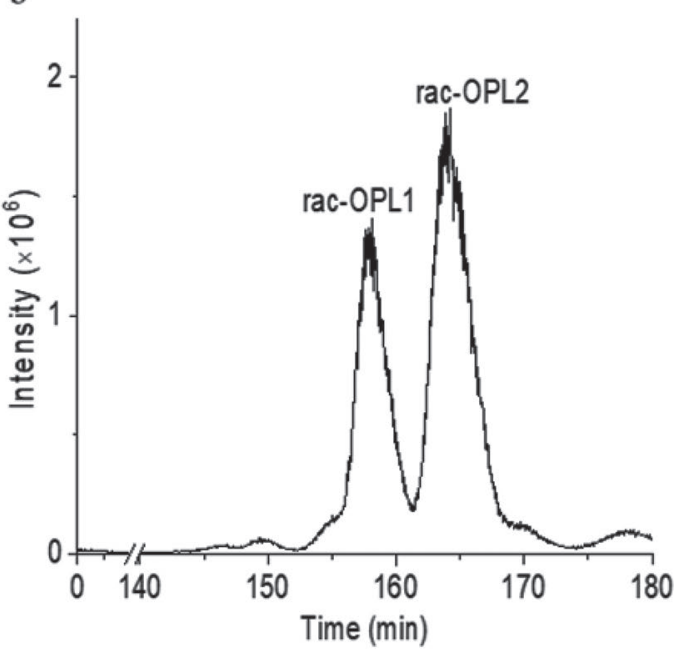

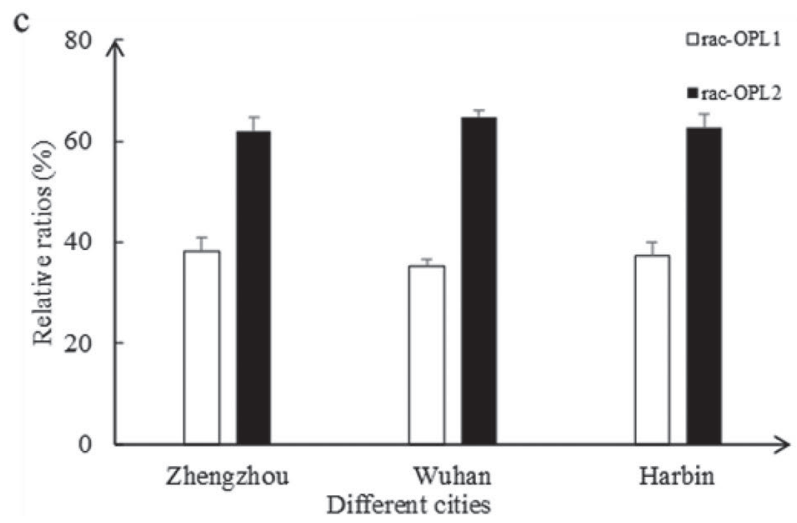

Figure 5. Chiral HPLC atmospheric pressure chemical ionization-MS analysis enantiomer pairs of rac-OPL (rac-OPL1 and rac-OPL2) in human milk. (a) Total ion chromatogram of enantiomer pairs of rac-OPL. (b) Extract ion chromatogram of enantiomer pairs of rac-OPL. (c) Relative ratios of enantiomers pairs of rac-OPL (rac-OPL1 and rac-OPL2) in human milk from Zhengzhou, Wuhan, and Harbin, China.

as described earlier. The results showed that the ion chromatogram of rac-OPL enantiomer pairs (rac-OPL1 and rac-OPL2) can be well extracted from the total ion chromatogram of human milk samples (Figure 5a, b). The results also showed that the 2 enantiomer pairs of rac-OPL in human milk were not equally distributed. In Zhengzhou, Wuhan, and Harbin human milk, the relative ratios of rac-OPL1 were $38.14,35.28$, and $37.81 \%$, respectively, and the relative ratios of rac-OPL2 were $61.86,64.72$, and $62.70 \%$, respectively (Figure 5c). There were no statistical differences among the 3 cities. In infants, about 10 to $30 \%$ of dietary lipids are first digested by gastric lipase, which specifically hydrolyzes the sn-3 position of TG (Bourlieu et al., 2014). The expression of pancreatic lipase is very different between adults and infants. In adults, small intestine lipid digestion is mainly performed by colipase-dependent PTL. In infants, the expression level of PTL is only $3 \%$ that of adults. The immaturity of PTL is compensated by pancreatic lipase-related protein 2 and bile salt-stimulated lipase (Andersson et al., 2011; Bourlieu et al., 2014; Casper et al., 2014). It has been reported that limited gastric hydrolysis of long-chain fatty acids plays a major role in the subsequent TG digestion by pancreatic lipase (Bernbäck et al., 1989; Bernbäck et al., 1990; Johnson et al., 2013). A hypothesis may be put forward that the unequal distribution of enantiomers pairs of rac-OPL may have important effects on lipid digestion in infants.

\section{CONCLUSIONS}

In human milk samples from 3 cities in China, Zhengzhou, Wuhan, and Harbin, OPL was the most abundant TG $(16.55,19.20$, and $18.67 \%$, respectively), followed by $\mathrm{OPO}(10.08,10.22$, and $12.03 \%$, respectively). The regioisomers of $\mathrm{PPO}$ (rac-PPO/rac-POP), OPO (rac-OPO/rac-OOP), LaOO (rac-LaOO/rac-OLaO), 
and POL (rac-OPL/rac-POL/rac-PLO) can be well analyzed by silver ion HPLC APCI-MS. The racemic TG of rac-PPO, rac-OPO, rac-OLaO, and rac-OPL were the main regioisomers of POP, OOP, OOLa, and POL, the relative ratios of which ranged from 93.81 to $94.41 \%, 85.59$ to $90.59 \%, 84.65$ to $88.46 \%$, and 71.95 to $74.97 \%$, respectively, in the 3 regions. In the case of the enantiomer pairs of rac-OPL in human milk, the distributions of rac-OPL1 and rac-OPL2 were not the same. In human milk from Zhengzhou, Wuhan, and Harbin, the relative ratios of rac-OPL2 $(61.86,64.72$, and $62.70 \%$, respectively) were higher than those of rac-OPL1 (38.14, 35.28, and $37.81 \%$, respectively).

\section{ACKNOWLEDGMENTS}

This work was financially supported by National Key R \& D of China 2018YFC160 4302, the Major Program for the Applied Technology R \& D Plan of Heilongjiang Province, China (GA16B201-2). The authors have not stated any conflicts of interest.

\section{REFERENCES}

Adlof, R., and G. List. 2004. Analysis of triglyceride isomers by silverion high-performance liquid chromatography. Effect of column temperature on retention times. J. Chromatogr. A 1046:109-113. https://doi.org/10.1016/j.chroma.2004.06.012.

Andersson, E.-L., O. Hernell, L. Bläckberg, H. Fält, and S. Lindquist. 2011. BSSL and PLRP2: Key enzymes for lipid digestion in the newborn examined using the Caco-2 cell line. J. Lipid Res. 52:1949-1956. https://doi.org/10.1194/jlr.M015685.

Barreiro, R., M. Diaz-Bao, A. Cepeda, P. Regal, and C. A. Fente. 2018. Fatty acid composition of breast milk in Galicia (NW Spain): A cross-country comparison. Prostaglandins Leukot. Essent. Fatty Acids 135:102-114. https://doi.org/10.1016/j.plefa.2018.06.002.

Beccaria, M., G. Sullini, F. Cacciola, P. Donato, P. Dugo, and L. Mondello. 2014. High performance characterization of triacylglycerols in milk and milk-related samples by liquid chromatography and mass spectrometry. J. Chromatogr. A 1360:172-187. https://doi .org/10.1016/j.chroma.2014.07.073.

Bernbäck, S., L. Bläckberg, and O. Hernell. 1989. Fatty acids generated by gastric lipase promote human milk tricylglycerol digestion by pancreatic colipase-dependent lipase. Biochim. Biophys. Acta 1001:286-293. https://doi.org/10.1016/0005-2760(89)90113-6.

Bernbäck, S., L. Bläckberg, and O. Hernell. 1990. The complete digestion of human milk triglycerol in vitro requires gastric lipase, pancreatic colipase-dependent lipase, and bile salt-stimulated lipase. J. Clin. Invest. 85:1221-1226. https://doi.org/10.1172/JCI114556.

Bourlieu, C., O. Menard, K. Bouzerzour, G. Mandalari, A. Macierzanka, A. R. Mackie, and D. Dupont. 2014. Specificity of infant digestive conditions: some clues for developing relevant in vitro models. Crit. Rev. Food Sci. Nutr. 54:1427-1457. https://doi.org/ 10.1080/10408398.2011.640757.

Bourlieu, C., and M. C. Michalski. 2015. Structure-function relationship of the milk fat globule. Curr. Opin. Clin. Nutr. Metab. Care 18:118-127. https://doi.org/10.1097/MCO.0000000000000138.

Casper, C., V. P. Carnielli, J. M. Hascoet, A. Lapillonne, L. Maggio, K. Timdahl, B. Olsson, M. Vågerö, and O. Hernell. 2014. rhBSSL improves growth and LCPUFA absorption in preterm infants fed formula or pasteurized breast milk. J. Pediatr. Gastroenterol. Nutr. 59:61-69. https://doi.org/10.1097/MPG.0000000000000365.
Folch, J., M. Lee, and G. H. Sloane-Stanley. 1957. A simple method for the isolation and purification of total lipids from animal tissues. J. Biol. Chem. 226:497-509.

Holčapek, M., H. Dvořáková, M. Lísa, A. J. Girón, P. Sandra, and J. Cvačka. 2010. Regioisomeric analysis of triacylglycerols using silver-ion liquid chromatography-atmospheric pressure chemical ionization mass spectrometry: comparison of five different mass analyzers. J. Chromatogr. A 1217:8186-8194. https://doi.org/10 .1016/j.chroma.2010.10.064.

Hu, J., F. Wei, X. Y. Dong, X. Lv, M. L. Jiang, G. M. Li, and H. Chen. 2013. Characterization and quantification of triacylglycerols in peanut oil by off-line comprehensive two-dimensional liquid chromatography coupled with atmospheric pressure chemical ionization mass spectrometry. J. Sep. Sci. 36:288-300. https://doi .org/10.1002/jssc. 201200567.

Johnson, K., L. Ross, R. Miller, X. Xiao, and M. E. Lowe. 2013. Pancreatic lipase-related protein 2 digests fats in human milk and formula in concert with gastric lipase and carboxyl ester lipase. Pediatr. Res. 74:127-132. https://doi.org/10.1038/pr.2013.90.

Kallio, H., M. Nylund, P. Bostrom, and B. Yang. 2017. Triacylglycerol regioisomers in human milk resolved with an algorithmic novel electrospray ionization tandem mass spectrometry method. Food Chem. 233:351-360. https://doi.org/10.1016/j.foodchem.2017.04 122 .

Kalpio, M., M. Nylund, K. M. Linderborg, B. Yang, B. Kristinsson, G. G. Haraldsson, and H. Kallio. 2015. Enantioselective chromatography in analysis of triacylglycerols common in edible fats and oils. Food Chem. 172:718-724. https://doi.org/10.1016/j.foodchem .2014.09.135.

Lísa, M., and M. Holčapek. 2013. Characterization of triacylglycerol enantiomers using chiral HPLC/APCI-MS and synthesis of enantiomeric triacylglycerols. Anal. Chem. 85:1852-1859. https://doi .org/10.1021/ac303237a.

Lísa, M., H. Velínská, and M. Holčapek. 2009. Regioisomeric characterization of triacylglycerols using silver-ion HPLC/MS and randomization synthesis of standards. Anal. Chem. 81:3903-3910. https://doi.org/10.1021/ac900150j.

Miles, E. A., and P. C. Calder. 2017. The influence of the position of palmitate in infant formula triacylglycerols on health outcomes. Nutr. Res. 44:1-8. https://doi.org/10.1016/j.nutres.2017.05.009.

Miliku, K., Q. L. Duan, T. J. Moraes, A. B. Becker, P. J. Mandhane, S. E. Turvey, D. L. Lefebvre, M. R. Sears, P. Subbarao, C. J. Field, and M. B. Azad. 2019. Human milk fatty acid composition is associated with dietary, genetic, sociodemographic, and environmental factors in the CHILD Cohort study. Am. J. Clin. Nutr. 110:1370-1383. https://doi.org/10.1093/ajcn/nqz229.

Momchilova, S., Y. Itabashi, B. Nikolova-Damyanova, and A. Kuksis. 2006. Regioselective separation of isomeric triacylglycerols by reversed-phase high-performance liquid chromatography: Stationary phase and mobile phase effects. J. Sep. Sci. 29:2578-2583. https:/ /doi.org/10.1002/jssc.200500504.

Momchilova, S.. K. Tsuji, Y. Itabashi, B. Nikolova-Damyanova, and A. Kuksis. 2004. Resolution of triacylglycerol positional isomers by reversed-phase high-performance liquid chromatography. J. Sep. Sci. 27:1033-1036. https://doi.org/10.1002/jssc.200401746.

Mu, H., and C. E. Høy. 2000. Effects of different medium-chain fatty acids on intestinal absorption of structured triacylglycerols. Lipids 35:83-89. https://doi.org/10.1007/s11745-000-0498-x.

Orsavova, J., L. Misurcova, J. V. Ambrozova, R. Vicha, and J. Mlcek. 2015. Fatty acids composition of vegetable oils and its contribution to dietary energy intake and dependence of cardiovascular mortality on dietary intake of fatty acids. Int. J. Mol. Sci. 16:1287112890. https://doi.org/10.3390/ijms160612871.

Pons, S. M., A. C. Bargalló, C. C. Folgoso, and M. C. López Sabater. 2000. Triacylglycerol composition in colostrum, transitional and mature human milk. Eur. J. Clin. Nutr. 54:878-882. https://doi .org/10.1038/sj.ejcn.1601096.

Qi, C., J. Sun, Y. Xia, R. Q. Yu, W. W. Wei, J. Y. Xiang, Q. Z. Jin, H. Xiao, and X. G. Wang. 2018. Fatty acid profile and the sn-2 position distribution in triacylglycerols of breast milk during different 
lactation stages. J. Agric. Food Chem. 66:3118-3126. https://doi .org/10.1021/acs.jafc.8b01085.

Řezanka, T., I. Kolouchová, A. Čejková, T. Cajthaml, and K. Sigler. 2013. Identification of regioisomers and enantiomers of triacylglycerols in different yeasts using reversed- and chiral-phase LC-MS. J. Sep. Sci. 36:3310-3320. https://doi.org/10.1002/jssc.201300657.

Řezanka, T., L. Nedbalová, and K. Sigler. 2016. Enantiomeric separation of triacylglycerols containing polyunsaturated fatty acids with 18 carbon atoms. J. Chromatogr. A 1467:261-269. https:// doi.org/10.1016/j.chroma.2016.07.006.

Řezanka, T., K. Pádrová, and K. Sigler. 2017. Regioisomeric and enantiomeric analysis of triacylglycerols. Anal. Biochem. 524:3-12. https://doi.org/10.1016/j.ab.2016.05.028.

Řezanka, T., and K. Sigler. 2014. Separation of enantiomeric triacylglycerols by chiral-phase HPLC. Lipids 49:1251-1260. https://doi .org/10.1007/s11745-014-3959-7.

Roman, C., F. Carriere, P. Villeneuve, M. Pina, V. Millet, U. Simeoni, and J. Sarles. 2007. Quantitative and qualitative study of gastric lipolysis in premature infants: Do MCT-enriched infant formulas improve fat digestion? Pediatr. Res. 61:83-88. https://doi.org/10 .1203/01.pdr.0000250199.24107.fb.

Sun, C., W. Wei, H. Su, X. Zou, and X. Wang. 2018a. Evaluation of sn-2 fatty acid composition in commercial infant formulas on the Chinese market: A comparative study based on fat source and stage. Food Chem. 242:29-36. https://doi.org/10.1016/j.foodchem 2017.09.005

Sun, C., W. Wei, X. Zou, J. Huang, Q. Jin, and X. Wang. 2018b. Evaluation of triacylglycerol composition in commercial infant formulas on the Chinese market: A comparative study based on fat source and stage. Food Chem. 252:154-162. https://doi.org/10 .1016/j.foodchem.2018.01.072.

Sun, C., X. Q. Zou, Y. P. Yao, J. Jin, Y. Xia, J. H. Huang, Q. Z. Jin, and X. G. Wang. 2016. Evaluation of fatty acid composition in commercial infant formulas on the Chinese market: A comparative study based on fat source and stage. Int. Dairy J. 63:42-51. https: //doi.org/10.1016/j.idairyj.2016.07.015.

Ten-Doménech, I., E. Beltrán-Iturat, J. M. Herrero-Martínez, J. V. Sancho-Llopis, and E. F. Simó-Alfonso. 2015. Triacylglycerol analysis in human milk and other mammalian species: Small-scale sample preparation, characterization, and statistical classification using HPLC-ELSD profiles. J. Agric. Food Chem. 63:5761-5770. https://doi.org/10.1021/acs.jafc.5b01158.
Tu, A., Q. Ma, H. Bai, and Z. Du. 2017. A comparative study of triacylglycerol composition in Chinese human milk within different lactation stages and imported infant formula by SFC coupled with Q-TOF-MS. Food Chem. 221:555-567. https://doi.org/10.1016/j .foodchem.2016.11.139.

Wan, J., S. Hu, K. Ni, G. Chang, X. Sun, and L. Yu. 2016. Characterisation of fecal soap fatty acids, calcium contents, bacterial community and short-chain fatty acids in Sprague Dawley rats fed with different sn-2 palmitic triacylglycerols diets. PLoS One 11:e0164894. https://doi.org/10.1371/journal.pone.0164894.

Wang, L., X. D. Li, M. Hussain, L. Liu, Y. Zhang, and H. Zhang. 2020. Effect of lactation stages and dietary intake on the fatty acid composition of human milk (A study in Northeast China). Int. Dairy J. 101:104580-104595. https://doi.org/10.1016/j.idairyj .2019.104580.

Zhao, P., S. Zhang, L. Liu, X. Pang, Y. Yang, J. Lu, and J. Lv. 2018. Differences in the triacylglycerol and fatty acid compositions of human colostrum and mature milk. J. Agric. Food Chem. 66:45714579. https://doi.org/10.1021/acs.jafc.8b00868.

Zou, L., G. Pande, and C. C. Akoh. 2016. Infant formula fat analogs and human milk fat: New focus on infant developmental needs. Annu. Rev. Food Sci. Technol. 7:139-165. https://doi.org/10 .1146/annurev-food-041715-033120.

Zou, X. Q., J. H. Huang, Q. Z. Jin, Z. Guo, Y. F. Liu, L. Z. Cheong, X. B. Xu, and X. G. Wang. 2013a. Lipid composition analysis of milk fats from different mammalian species: Potential for use as human milk fat substitutes. J. Agric. Food Chem. 61:7070-7080. https:// doi.org/10.1021/jf401452y.

Zou, X. Q., J. H. Huang, Q. Z. Jin, Z. Guo, Y. F. Liu, L. Z. Cheong, X. B. Xu, and X. G. Wang. 2013b. Model for human milk fat substitute evaluation based on triacylglycerol composition profile. J. Agric. Food Chem. 61:167-175. https://doi.org/10.1021/jf304094p.

\section{ORCIDS}

Zhuang Yu (ํ) https://orcid.org/0000-0003-1676-135X

H. X. Yi ๑ https://orcid.org/0000-0002-8968-4263

L. W. Zhang @ https://orcid.org/0000-0003-3459-2975 